\title{
Extranjeros entre dos mundos: una aproximación proporcional a las colonias de mercaderes extranjeros en Sevilla, 1570-1650
}

\author{
por Eberhard Crailsheim
}

\begin{abstract}
This paper analyzes the foreign presence in the commerce of Seville during the Golden Age of Spain. As a hub between Europe and America, the city attracted a considerable number of foreigners who participated in the commerce with both continents. In the majority of cases, their role was seen as negative by the Spanish observers, as they allegedly were in charge of almost 90 percent of the Indies trade. This article examines several sources to ascertain the proportions between the different foreign nations, as well as the relations between Spaniards and foreigners among the richest merchants of the city. Documents from the notaries of Seville prove to be most relevant, as well as tax lists of merchants. First, the period between 1570 and 1650 is considered as a whole to differentiate the foreigners from various regions of Europe. Second, the scrutiny of sample years gives information of the changes that occurred during the time of consideration. And third, the analysis of various tax lists offers a picture of the proportions between Spaniards and foreigners in the American and European commerce of the city.
\end{abstract}

Había dos monopolios en los cuales se basaba el sistema mercantilista hispanoamericano en la edad moderna: primero, sólo podían participar españoles y segundo, Sevilla era el único puerto entre los dos mundos. Ambos principios fueron burlados ampliamente. ${ }^{1}$ Aunque hasta al menos 1650 Sevilla desempeñó efectivamente un papel importante para el comercio indiano ${ }^{2}$ había extranjeros en la Carrera

1 Antonio García-Baquero González, La carrera de Indias. Suma de la contratación y océano de negocios (Sevilla 1992), pp. 24-32.

2 Pablo E. Pérez-Mallaína, "Auge y decadencia del puerto de Sevilla como cabecera de las rutas indianas”: Caravelle 69 (1997), pp. 15-39. 
de Indias desde el principio. ${ }^{3}$ Unos participaron de forma clandestina, evadiendo la ciudad de Sevilla, ${ }^{4}$ mientras que otros se domiciliaron en Sevilla y se involucraron indirectamente en el comercio indiano. ${ }^{5} \mathrm{La}$ presencia de estos últimos fue pormenorizada por los cronistas, frailes, oficiales y poetas de España. ${ }^{6}$

"Al olor, y, sobre todo, al sabor de estas cuantiosísimas riquezas, gran parte de las cuales quedaba en Sevilla, vivían en la magnífica ciudad del Guadalquivir, quiénes como vecinos, gozando las franquicias y exenciones de tales, quiénes como residentes, y quiénes como meros estantes ó transeúntes, no sólo millares y millares de personas de toda España, sino también una muchedumbre crecidísima de extranjeros, en especial, de italianos, flamencos y franceses, cada cual en busca de su avío y en solicitud de su medra; cada cual discurriendo medios é inventando artes, artimañas ó artificios para apropiarse, industriosa y más ó menos limpiamente, alguna mielecilla de las óptimas colmenas indianas, consolándose así de no haber sido ellos ni sus naciones los que tuvieron la dicha de descubrir y conquistar el Nuevo Mundo."

El papel de los extranjeros dentro del comercio indiano era evidente y Sancho de Moncada, uno de los arbitristas de la época de Felipe III, lo pone muy claro cuando cuenta que

3 Juan M. Morales Álvarez, Fuentes para la historia colonial de Venezuela: Extranjeros con Carta de Naturaleza de las Indias, durante la segunda mitad del siglo XVIII (Caracas 1980), pp. 25-27; Peter Boyd-Bowman, "La procedencia de los españoles de América: 1540-1559": Historia Mexicana 17, 1 (1967), pp. 37-71, aquí pp. 39-42.

4 Ildefonso Pulido Bueno, Almojarifazgos y comercio exterior en Andalucía durante la época mercantilista 1526-1740 (Huelva 1993); Ángel Alloza Aparicio, Europa en el mercado español. Mercaderes, represalias y contrabando en el siglo XVII (Salamanca 2006).

5 Enriqueta Vila Vilar, "Los europeos en el comercio americano. Sevilla como plataforma": Renate Pieper/Peer Schmidt (eds.), Latin America and the Atlantic World/El mundo atlántico y América Latina (1500-1850). Essays in Honor of Horst Pietschmann (Köln 2005), pp. 279-296.

6 Tomas de Mercado, Suma de tratos y contratos (Sevilla 1571), 1. II, cap. VI; Alonso de Morgado, Historia de Sevilla (Sevilla 1587), ff. 57r-57r; Félix Lope de Vega Carpio, El Arenal de Sevilla (Madrid 1618); Joseph de Veitia Linaje, Norte de la Contratación de las Indias Occidentales (Sevilla 1672), 1. I, cap. XXXI; Héctor Brioso Santos, Sevilla en la prosa de ficción del Siglo de Oro (Sevilla 1998), pp. 152-154.

7 Miguel de Cervantes Saavedra, Rinconete y Cortadillo (Sevilla 1905, original de 1613), p. 12. 
"[...] los Extranjeros negocian [...] en las Indias de diez partes, las nueve: de modo que las Indias son para ellos, y el título de V. Majestad, pues las flotas enteras les vienen consignadas." 8

La presencia de los extranjeros fue considerada en gran parte como un agobio para la ciudad, el país y hasta para el Imperio. Debido a las doctrinas mercantiles, su participación en el comercio indiano no era deseada, y más aún, estaba prohibida. ${ }^{9}$ A pesar de esta veda, eran constantes las quejas presentadas ante el rey por los arbitristas y comerciantes sevillanos contra los agravios que causaron:

" [...] nos tratan como a Indios, sacando grandes sumas de fruslerías, y juguetes, que son de gran perjuicio por superfluas, y contra toda ley de buen gobierno, y de buen comercio, pues el comercio se introdujo para traer cosas necesarias, y llevar las superfluas, y en España se hace al revés, que sacan materiales, y plata, y traen fruslerías." ${ }^{10}$

Aunque las acusaciones de Sancho de Moncada parecen exageradas, plantean varias preguntas acerca de la presencia extranjera en Sevilla. ¿Quiénes fueron estos extranjeros? y ¿era realmente tan elevado su número?

Los extranjeros han sido estudiados con profundidad por la historiografía debido a la importancia que se les atribuye como una de las causas de la decadencia de España. Objeto de investigación fueron, por un lado, los grandes banqueros de Alemania, Génova y Portugal, ${ }^{11}$ y por el otro los grandes mercaderes extranjeros de Sevilla. Se trata, entonces, de consideraciones generales, como por ejemplo de Antonio Domínguez Ortiz o de Hermann Kellenbenz, ${ }^{12}$ pero también de inves-

8 Sancho de Moncada, Restauración política de España (Alicante 1999, original de 1619), cap. XII, 8v.

9 Recopilación de las Leyes de Indias (1680), libro 9, título 27.

${ }_{10}$ Moncada, Restauración política de España (nota 8), cap. XII, 8v-9r.

11 Ramón Carande y Thovar, Historia del mundo moderno: Carlos $V$ y sus banqueros (Barcelona 1987); Carlos Álvarez Nogal, Los banqueros de Felipe IV y los metales preciosos americanos, 1621-1665 (Madrid 1997).

12 Antonio Domínguez Ortiz (ed.), Los extranjeros en la vida española durante el siglo XVII y otros artículos (Sevilla 1996); Hermann Kellenbenz (ed.), Fremde Kaufleute auf der Iberischen Halbinsel (Köln/Wien 1970); también Enrique Otte/Antonio Miguel Bernal, Sevilla y sus mercaderes a fines de la Edad Media (Sevilla 1996); Rolf Walter, "Fremde Kaufleute in Sevilla im 16. Jahrhundert": Rainer Gömmel/Markus A. Denzel/ Jürgen Schneider (eds.), Weltwirtschaft und Wirtschaftsordnung. Festschrift für Jürgen Schneider zum 65. Geburtstag (Stuttgart 2002), pp. 45-56; María Begoña Villar García/ Pilar Pezzi Cristóbal (eds.), Los extranjeros en la España Moderna. Actas del I Coloquio Internacional, celebrado en Málaga del 28 al 30 de noviembre de 2002 (Málaga 2003). 
tigaciones sobre diferentes naciones, ${ }^{13}$ como las de Enriqueta Vila Vilar o la obra clásica de Albert Girard. ${ }^{14}$ Algunos estudios incluyen listas de mercaderes de Sevilla cuyas remesas fueron confiscadas por el rey o listas de miembros de diferentes consulados de la ciudad. ${ }^{15}$ Sin embargo, hasta este momento no se ha realizado un esquema conciso de las diferentes nacionalidades presentes en Sevilla durante la época de su apogeo, comparando la presencia de flamencos con la de portugueses, genoveses, etc. Tampoco sabemos el número de extranjeros que participaron en el comercio de Sevilla frente a los españoles que estaban en la ciudad. Por lo tanto, el presente trabajo intenta llenar este vacío con una aproximación a estas proporciones.

${ }_{13}$ Para el concepto de la nación extranjera, véase por ejemplo Ana Crespo Solana, "Nación extranjera y cofradía de mercaderes. El rostro piadoso de la integración social": Begoña Villar García/Pezzi Cristóbal, Los extranjeros en la España Moderna (nota 12), pp. $175-187$.

${ }_{14}$ Albert Girard, El comercio francés en Sevilla y Cádiz en tiempos de los Habsburgo. Contribución al estudio del comercio extranjero en la España de los siglos XVI al XVIII (Sevilla 2006); Enriqueta Vila Vilar, Los Corzo y los Mañara. Tipos y arquetipos del mercader con Indias (Sevilla 1991); véase también Ángel Alloza Aparicio, "El comercio francés en España y Portugal. La represalia de 1635": Carlos Martínez Shaw/ José María Oliva Melgar (eds.), El sistema atlántico español, siglos XVII-XIX (Madrid 2005), pp. 127-161; Ruth Pike, Enterprise and Adventure. The Genoese in Seville and the Opening of the New World (Ithaca 1966); Eddy Stols, De Spaanse Brabanders of de Handelsbetrekkingen der Zuidelijke Nederlanden met de Iberische Wereld 1598-1648 (Bruxelles 1971); John G. Everaert, De internationale en koloniale Handel der Vlaamse Firma's te Cadiz, 1670-1700 (Brugge 1973); Pedro Collado Villalta, "El embargo de bienes de los portugueses en la flota de Tierra Firme de 1641": Anuario de estudios americanos 36 (1979), pp. 169-207; José Manuel Díaz Blanco, "La Corona y los cargadores a Indias portugueses de Sevilla, 1583-1645": Felipe Lorenzana de la Puente/Francisco J. Mateos Mateos Azcacibar (coords.), Iberismo - Las relaciones entre España y Portugal. Historia y tiempo actual y otros estudios sobre Extremadura (Llerena 2007), pp. 91-104.

15 Juana Gil-Bermejo García, "Mercaderes sevillanos. Una nómina de 1637”: Archivo Hispalense 181 (1976), pp. 183-197; Enriqueta Vila Vilar, "Una amplia nómina de los hombres de comercio sevillano del S. XVII": Minervae baeticae: Boletín de la Real Academia Sevillana de Buenas Letras 30 (2002), pp. 139-191; Jesús Aguado de los Reyes, "Lisboa, Sevilla, Amberes, eje financiero y comercial en el sistema atlántico, primera mitad del siglo XVII": Carlos Martínez Shaw/José María Oliva Melgar (eds.), El sistema atlántico español, siglos XVII-XIX (Madrid 2005), pp. 101-126; Eufemio Lorenzo Sanz, Comercio de España con América en la época de Felipe II (Valladolid 1986). 
Para averiguar el número de extranjeros en Sevilla, una aproximación se puede llevar a cabo con la inspección de las oficinas de protocolos de los notariados, las llamadas escribanías. Existían unas 24 escribanías en la ciudad en el siglo de oro, que contenían obligaciones, cartas de pago, poderes, etc. Hay que ser consciente de que al utilizar los fondos notariales como fuente, se dejan de lado los contratos informales que no están presentes en las escribanías. Sin embargo, se puede partir de la práctica de los vascos en este comercio, que recurrieron al servicio del notariado en cuanto se tratase de contratos de un valor de más de 50 ducados. ${ }^{16}$ Así es de suponer que la mayor parte del gran comercio de la ciudad puede ser estudiado a través de este tipo de documentación. Con respecto a esto, es un problema que a menudo los extranjeros no indicaran su origen en los contratos. Por lo tanto, para saber el origen de un mercader, hacen falta fuentes adicionales, como por ejemplo documentación sobre las naturalizaciones. ${ }^{17}$ Otra dificultad se ve representada por la distinción correcta de las nacionalidades de los extranjeros. Esta tarea es difícil, por un lado debido a los diferentes conceptos de patria y nación. ${ }^{18}$ Así se puede entender que el comercio indiano fue permitido a castellanos, tolerado en cuanto se tratase de vascos y aragoneses, pero prohibido para los demás súbditos de la Corona española, de los Países Bajos, Portugal y Génova. ${ }^{19}$ Por otro lado, resulta problemático simplemente porque las fronteras cambiaron (por ejemplo entre Francia y los Países Bajos) al igual que las declaraciones de los mercaderes, que cambiaron su procedencia como mejor les pareciera (por ejemplo entre alemán, flamenco y holandés). Esta dificultad también puede ser superada par-

${ }^{16}$ Lutgardo García Fuentes, "El crédito comercial en la Carrera de Indias, 15801630": María Justina Sarabia Viejo/Javier Ortiz de la Tabla Ducasse/Pablo Emilio Pérez-Mallaina Bueno/José Jesús Hernández Palomo (eds.), Entre Puebla de los Ángeles y Sevilla. Estudios americanistas en homenaje al Dr. José Antonio Calderón Quijano (Sevilla 1997), pp. 133-150, aquí p. 137.

17 Otras fuentes útiles para tal propósito se encuentran por ejemplo publicados en Stols, De Spaanse Brabanders (nota 14); y en Collado Villalta, "El embargo de bienes de los portugueses" (nota 14).

${ }_{18}$ Xavier Gil Pujol, "Un rey, una fe, muchas naciones. Patria y nación en la España de los siglos XVI-XVII": Antonio Álvarez-Ossorio Alvariño/Bernardo José García García (eds.), La Monarquía de las Naciones. Patria, nación y naturaleza en la monarquía de España (Madrid 2004), pp. 39-76.

19 Antonio Domínguez Ortiz, "La concesión de 'Naturalezas para comerciar con Indias' durante el siglo XVII”: Revista de Indias 76 (1959), pp. 227-239, aquí: p. 227. 
cialmente con la aplicación de fuentes complementarias. Finalmente, hay que preguntarse cómo clasificar a los jenízaros, los hijos de extranjeros nacidos en España. ${ }^{20}$ En su real cédula de 1620, Felipe III los tomó por naturales de sus reinos, a pesar de las acusaciones presentadas contra ellos. ${ }^{21}$ No obstante, en muchos casos los jenízaros tenían los mismos problemas con los cuales tenían que enfrentarse también sus padres extranjeros. ${ }^{22} \mathrm{Al}$ considerar además que como mercaderes siguieron utilizando los lazos familiares para el comercio con su patria, en este trabajo serán clasificados como extranjeros.

\section{LOS EXTRANJEROS EN LOS CONTRATOS NOTARIALES Y LAS NATURALIZACIONES}

Como punto de partida del análisis, se pueden ver las diferentes nacionalidades de los extranjeros en los contratos de las escribanías de Sevilla. En el gráfico 1 se muestra el resultado de la investigación de 1.700 documentos del Archivo de Protocolos de Sevilla. ${ }^{23}$

Con $37 \%$, o sea un número absoluto de 413 nombres, el grupo de los flamencos y holandeses es dominante en el comercio de Sevilla. De este número, 384 declararon ser de las provincias obedientes (los llamados flamencos), mientras que 29 reconocieron ser de las provincias insurgentes (los llamados holandeses). La división entre estos dos grupos es muy compleja o hasta imposible. A los holandeses no se les permitió participar en el comercio español durante muchos años a lo largo de la Guerra

${ }_{20}$ Margarita García Mauriño Mundi, La pugna entre el Consulado de Cádiz y los jenízaros por las exportaciones a Indias, 1720-1765 (Sevilla 1999), pp. $43 \mathrm{ff}$.

${ }_{21}$ Ibidem, p. 44. Recopilación de las Leyes de Indias (nota 9), libro 9, título 27, ley 27.

22 José Manuel Díaz Blanco/Natalia Maillard Álvarez, “¿Una intimidad supeditada a la ley? Las estrategias matrimoniales de los cargadores a indias extranjeros en Sevilla, siglos XVI-XVII": Nuevo Mundo Mundos Nuevos (2008), publicado en línea, http// nuevomundo.revues.org/index28453.html, p. 4.

${ }^{23}$ Los datos (incluyendo a 1.106 extranjeros) fueron recogidos en el Archivo de Protocolos de Sevilla (en adelante APS) proviniendo de varias oficinas notariales, incluyendo los legajos 1607, 2607, 3494, 3607, 3697, 6979, 7420, 7421, 7496, 7497, 9390, 9983, 9984, 10060, 10996, 16714, 16715, 16766, 16867, 16869, 16870, 16969, 16979, 17869, 18484. Véase Eberhard Crailsheim, Seville and the European Atlantic Trade. A Network Study of French and Flemish Merchant Communities in Early Modern History, 1580-1640 (tésis doctoral, Universidad de Graz 2008). El gráfico 1 también incluye personas del Archivo General de Indias (en adelante AGI), sin alterar apenas las relaciones globales. 
de los Ochenta Años. ${ }^{24}$ Por eso, muchos de ellos se declararon flamencos, lo que imposibilita una clara división entre estos dos colectivos. ${ }^{25}$

GrÁFICO 1: EXTRANJEROS EN LOS CONTRATOS DE LAS ESCRIBANÍAS DE SEVILLA, 1570-1650

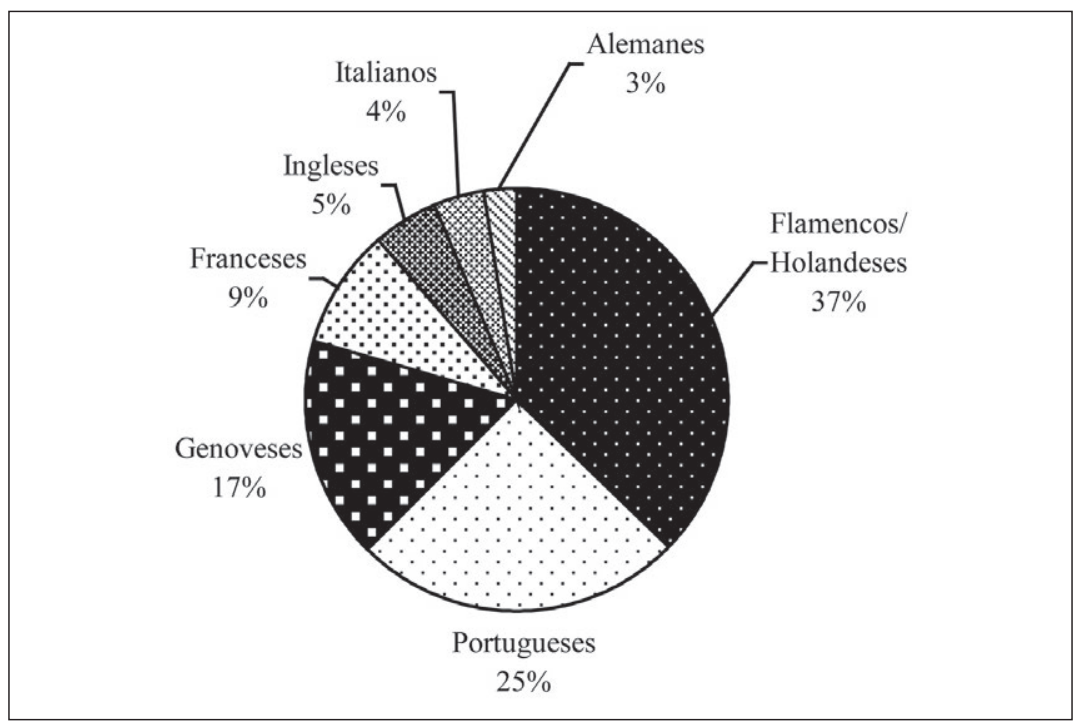

El segundo grupo es el de los portugueses con $25 \%$, o sea 277 personas, seguidos por los genoveses con $17 \%$ (188), los franceses con $9 \%$ (102), los ingleses con $5 \%$ - que incluye a irlandeses y escoceses (56) -, los italianos no provenientes de Génova con 4\% (42), y finalmente los alemanes con $3 \%(28){ }^{26}$

Para verificar estos datos, se pueden utilizar los expedientes de naturalización en el Archivo General de Indias. ${ }^{27}$ Para los mercaderes

24 Jonathan Irvine Israel, "España, los embargos españoles y la lucha por el dominio del comercio mundial": Revista de Historia Naval 23, 6 (1988), pp. 89-105.

25 Ana Crespo Solana, Mercaderes atlánticos. Redes del comercio flamenco y holandés entre Europa y el Caribe (Córdoba 2009), p. 109.

${ }^{26}$ Respecto al último grupo de los alemanes, se tiene que tomar en cuenta que figuraban en el mismo consulado que los flamencos y que algunos de ellos seguramente pasaban erróneamente por flamencos.

27 AGI Contratación 50A, 50B, 51A, 51B, 596A, 596B. 
extranjeros, las naturalizaciones constituían la única vía de participar legalmente de modo directo en el comercio indiano. Mientras que la mayoría de ellos participó indirectamente en este comercio con la ayuda de mercaderes locales ${ }^{28}$ una minoría pidió la naturalización con licencia especial para el comercio. Con tal licencia podían participar en el comercio sin intermediarios españoles.$^{29}$ La obtención de las naturalizaciones era, por lo general, un proceso largo y costoso. Sólo podían ser pedidas por los mercaderes más pudientes, y estos las solicitaron con el único propósito de participar en el comercio de Indias. ${ }^{30}$ Los mencionados mercaderes habían vivido durante muchos años en Sevilla o en los alrededores y estaban integrados en la sociedad española, sin perder necesariamente el apego a sus compatriotas. ${ }^{31}$ A partir de 1616 se exigió para la naturalización haber vivido en España al menos 20 años, de los cuales diez con casa poblada; estar casado con mujer natural de los reinos de España y poseer al menos 4.000 ducados en bienes raíces. Además, sólo debían llevar a cabo sus relaciones comer-

${ }^{28}$ Para participar en el comercio indiano, los mercaderes extranjeros se sirvieron sobre todo de la venta fiada, que fue ratificada en forma de obligación ante el escribano. Ésta era un sistema mercantil en el cual los agentes españoles hicieron de poseedores de las mercadurías que les fueron abastecidos por los extranjeros. Una vez que los empleados o agentes de los intermediarios sevillanos regresaron de América con las ganancias de las mercadurías vendidas, pasaron a ser los caudales de los extranjeros. Jacob van Klaveren, Europäische Wirtschaftsgeschichte Spaniens im 16. und 17. Jahrhundert (Stuttgart 1960), pp. 110-125; García Fuentes, "El crédito comercial en la Carrera de Indias" (nota 16), pp. 135-137; Maria Guadalupe Carrasco González, Los instrumentos del comercio colonial en el Cádiz del siglo XVII, 1650-1700 (Madrid 1996); AntonioMiguel Bernal Rodríguez, La financiación de la Carrera de Indias, 1492-1824. Dinero y crédito en el comercio colonial español con América (Sevilla/Madrid 1992).

${ }_{29}$ Antonio Domínguez Ortiz, "Los extranjeros en la vida española durante el siglo XVII”: idem, Los extranjeros en la vida española (nota 12), pp. 17-182, aquí: p. 147.

${ }^{30}$ Idem, "La concesión de 'Naturalezas para comerciar con Indias"” (nota 19); Díaz Blanco, "La Corona y los cargadores a Indias portugueses de Sevilla" (nota 14). Como señaló Tamar Herzog, la naturalización en España fue adquirida en la mayor parte sin documentos, sólo por la costumbre y la reputación, dependiendo de la comunidad local. No obstante, en situaciones especificas, como en el caso del comercio de América, era necesario pedir naturaleza por el rey para adquirir o confirmar ciertos derechos. Tamar Herzog, Defining Nations. Immigrants and Citizens in Early Modern Spain and Spanish America (New Haven/London 2003), pp. 5, 201-208.

${ }^{31}$ Eberhard Crailsheim, "Les marchands français à Séville, 1580-1650. Les examples de Pedro de la Farxa, Lanfran David et Pedro de Alogue": Jean-Philippe Priotti/Guy Saupin (eds.), Commerce atlantique franco-espagnol (Rennes 2008), pp. 233-248. 
ciales utilizando capitales propios. ${ }^{32} \mathrm{El}$ número de los naturalizados era pequeño: en el periodo entre 1570 y 1650, un total de 286 mercaderes solicitó la naturalización en Sevilla, representando un promedio de 3,6 naturalizaciones por año. Se puede hablar de "una inmigración de alta calidad, pero de escaso volumen". ${ }^{33}$ Sin embargo, dado que se trataba exclusivamente de mercaderes ricos, la documentación puede servir para dar otra perspectiva sobre la distribución de los orígenes de estos extranjeros y puede ser observada en el gráfico $2 .{ }^{34}$

GrÁFico 2: Solicitudes PARA NATURALIZACión En SEVILLA, 1570-1650

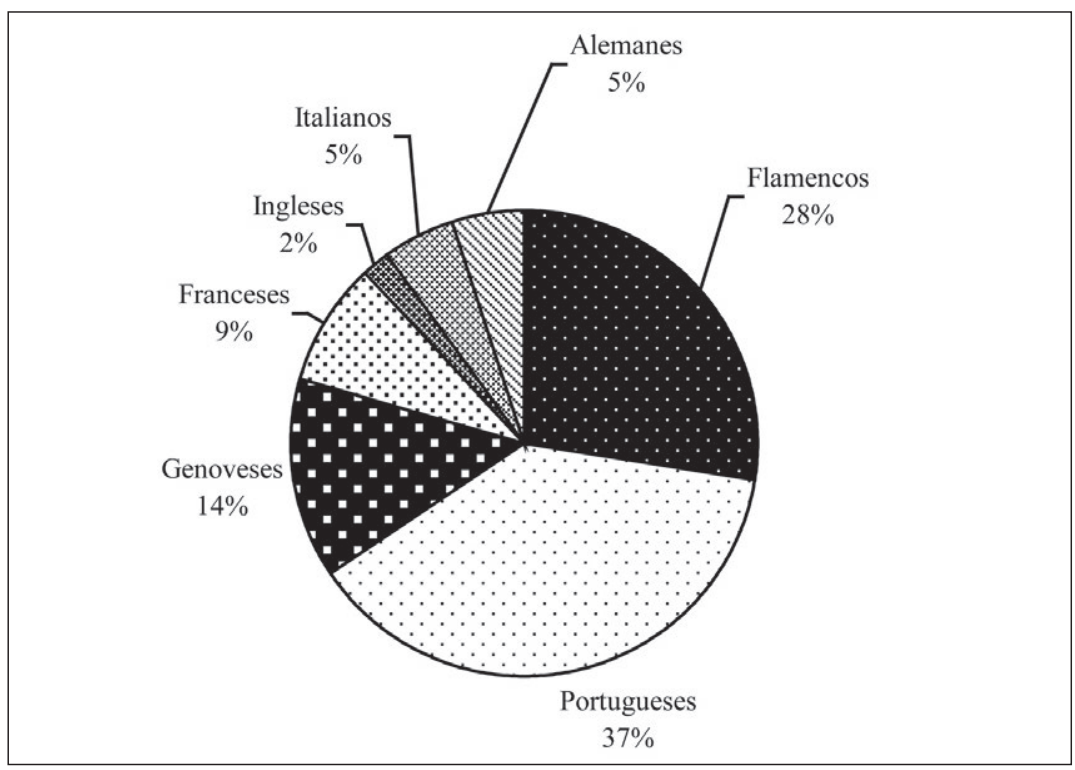

En este gráfico se puede contemplar que la nación dominante es la de los portugueses con $37 \%$, o sea 108 mercaderes, seguido por el grupo de los flamencos (ningún holandés figura entre los naturalizados) con $28 \%$ (79). Después vienen los genoveses con $14 \%$ (40), los franceses

${ }^{32}$ La legislación cambió varias veces, por ejemplo en 1568, 1592, 1608 y en 1616. AGI Contratación 50B, s.f; Domínguez Ortiz, "La concesión de 'Naturalezas para comerciar con Indias"” (nota 19), pp. 227-228.

${ }^{33}$ Idem, "Los extranjeros en la vida española" (nota 21), p. 47.

${ }^{34}$ El gráfico se compone por las cartas de naturalización entre 1575 y 1650 (cf. nota 27). 
con $9 \%$ (25), los alemanes (15) e italianos no genoveses (14) cada uno con $5 \%$ y los ingleses con $2 \%(5){ }^{35}$

Entre los comerciantes naturalizados se encuentran las mismas naciones como en el gráfico anterior. La diferencia más importante entre los dos resultados es que en los documentos notariales hay más flamencos, aunque había más portugueses que intentaron naturalizarse. Una explicación para esta discrepancia puede encontrarse en el carácter especial de algunas de las naturalizaciones, ya que no todas fueron otorgadas por vía legal, sino también por la vía de gracia. Estas últimas fueron concedidas por el rey a algunos notables mercaderes a cambio de favores recibidos ${ }^{36}$ A menudo se trataba de un asiento, es decir, de un contrato que servía como un tipo de crédito para la Corona a cambio de ciertos derechos. Para tal modelo de naturalización, no hacía falta cumplir las condiciones previstas por la ley y no era necesario que la persona naturalizada residiese en Sevilla. Este tipo de naturalización fue también conseguida por el asentista para que alguien pudiera viajar a las Indias en su nombre, lo que básicamente significa que personas con tales naturalizaciones posiblemente no residiesen en Sevilla y nunca fuesen a las escribanías de la ciudad, dejando el proceso del envío y recibo a intermediarios ya establecidos en Sevilla (extranjeros o naturales). El grupo más grande que recibió naturalizaciones por la vía de gracia es conocido: se trata de los portugueses, que actuaron como banqueros en la Corte de Felipe IV, favorecidos por la política del conde-duque de Olivares. ${ }^{37}$ Entre 1629 y 1639, P. Collado Villalta enumeró a 13 portugueses que adquirieron tales naturalizaciones. ${ }^{38}$ Esto puede ser una explicación para el número superior de las naturalizaciones portuguesas con respecto a su presencia en los protocolos.

${ }^{35}$ Los datos (tomados del AGI) recogidos por Domínguez Ortiz, "Los extranjeros en la vida española" (nota 21), pp. 137-164, muestran diferencias menores, pero por lo general se parecen: 267 extranjeros naturalizados entre 1570 y 1650: $38 \%$ portugueses, $31 \%$ flamencos, $11 \%$ genoveses, $8 \%$ franceses, $6 \%$ alemanes, $4 \%$ italianos (no genoveses) y $2 \%$ ingleses.

${ }^{36}$ En su artículo sobre estrategias matrimoniales, José Manuel Díaz Blanco y Natalia Maillard Álvarez razonan aun que la mayoría de las cartas de naturaleza fueron vendidas (vía de gracia): Díaz Blanco/Maillard Álvarez, “ ¿Una intimidad supeditada a la ley?" (nota 22); véase también Díaz Blanco, "La Corona y los cargadores a Indias portugueses a Sevilla" (nota 14), p. 97.

${ }^{37}$ Ibidem, pp. 99-101.

38 Collado Villalta, "El embargo de bienes de los portugueses" (nota 14), especialmente: pp. 176-177, 190. 


\section{LAS FluCtUACIONES A LO LARGO DE LOS AÑOS}

Además de investigar la composición de los extranjeros en Sevilla a lo largo de los 80 años que transcurrieron entre 1570 y 1650, también es de interés indagar sobre el cambio en el número absoluto de los extranjeros en Sevilla, igual que en el de las proporciones entre los extranjeros. Antonio Domínguez Ortiz indicó las fechas exactas de las concesiones de naturalización, con el resultado mostrado en gráfico $3 .^{39}$

Si descartamos el pequeño numero de naturalizaciones del siglo XVI, el gráfico muestra que en la primera mitad del siglo XVII hubo momentos en que se llevaron a cabo muchas naturalizaciones y otros en que se realizaron muy pocas. En el reinado de Felipe III (1598-1621) se ve un pico en 1608/9 (20 naturalizaciones) que se puede explicar por la naturalización de diez portugueses y seis flamencos. En el reino de Felipe IV (1621-1665), hay un periodo entre 1629 y 1643 que se puede considerar como la época más prolífera en lo referente a las naturalizaciones, con un total de 149 naturalizados, es decir, un promedio aproximado de once por año. Esta cifra incluye a 55 portugueses, 43 flamencos, 19 genoveses, diez franceses, diez alemanes, dos italianos (no oriundos de Génova), dos ingleses y ocho mercaderes de otras naciones. Durante esta época, las proporciones entre los naturalizados permanecieron relativamente constantes respecto a las cifras del total de los 80 años investigados. Sólo el grupo de los italianos (no genoveses) baja considerablemente durante esta época de un promedio total de 5,2\% a 1,4\%, mientras que el aporte de alemanes aumenta ligeramente de 4,9 a 7,1\%. Las mencionadas 13 naturalizaciones portuguesas por vía de gracia fueron otorgadas justamente durante estos años de boom descritos anteriormente. Sin tomar en cuenta a estos portugueses, que fueron naturalizados por la vía de gracia, los flamencos sobrepasan a los portugueses durante estos 14 años, con 43 y 42 respectivamente. ${ }^{40}$ Esto confirma la información de los protocolos notariales, y se puede concluir que los portugueses no estaban más presentes en Sevilla que los flamencos.

${ }^{39}$ Grafico reconstruido a través de los datos elaborados por Domínguez Ortiz, "Los extranjeros en la vida española" (nota 21).

40 No conocemos el número de las naturalizaciones flamencas por la vía de gracia durante esta época, pero sí se puede suponer que los respectivos flamencos residían en la ciudad de Sevilla. A diferencia de los portugueses, el número de banqueros flamencos en la corte de Felipe IV era mínimo. 
Gráfico 3: Concesiones de Cartas de naturales en Sevilla, $1600-1650$

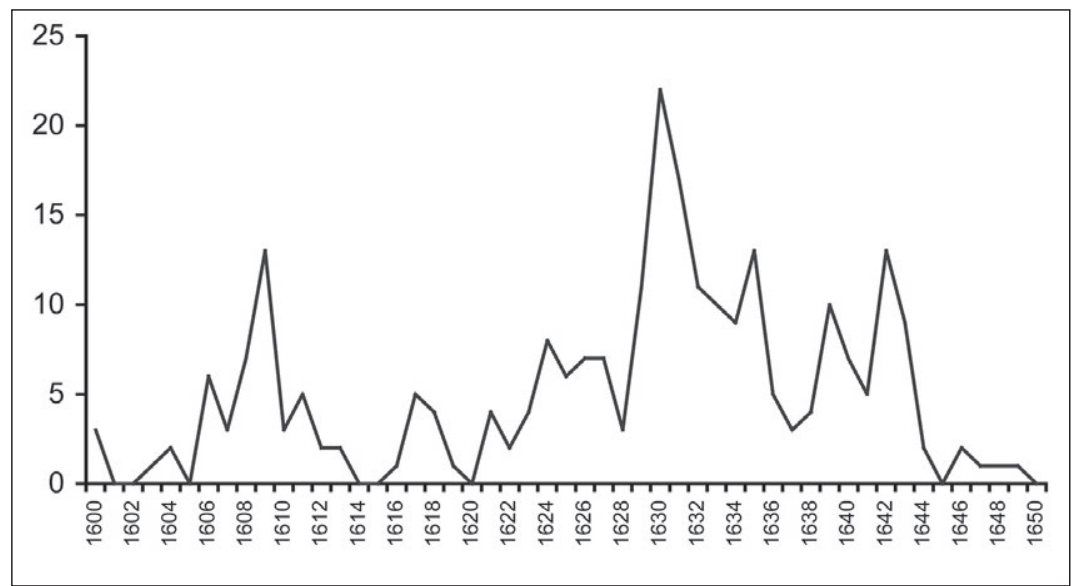

Para poder hacer una comparación con los datos notariales, es decir, para investigar el desarrollo en las actividades comerciales de la ciudad de Sevilla, hay que utilizar otro método. Diferentes legajos de los años 1580, 1600, 1620 y 1640 fueron examinados para suministrar una muestra representativa ${ }^{41}$ Los detalles se pueden encontrar a continuación en la tabla 1.

TABLA 1: ANÁLISIS DE DOCUMENTOS DEL APS

\begin{tabular}{l|c|c|c}
\hline Años & Documentos & Doc. con extranjeros & Porcentaje \\
\hline 1580 & 229 & 82 & $36 \%$ \\
1600 & 321 & 225 & $70 \%$ \\
1620 & 838 & 560 & $67 \%$ \\
1640 & 297 & 192 & $65 \%$ \\
\hline TOTAL & 1685 & 1059 & $63 \%$ \\
\hline
\end{tabular}

${ }^{41}$ Para las fuentes detalladas, véase nota 23. 
De los 1.685 documentos estudiados, 1.059 contienen nombres de extranjeros, o sea un $63 \% .{ }^{42} \mathrm{El}$ año 1580 es de especial interés porque sólo $36 \%$ de los documentos contienen referencias a extranjeros. Después se puede ver un auge enorme en el número de extranjeros en la ciudad hasta 1600 , cuando va aumentando su presencia en los documentos a un $70 \%$. Luego, entre 1600 y 1640 la presencia extranjera en Sevilla permanece relativamente constante, bajando ligeramente de 70 a $65 \%$. Resumiendo, se puede observar que el aumento de las naturalizaciones otorgadas no está relacionado directamente con la cuota de extranjeros en la ciudad. Con respecto a las nacionalizaciones después de 1629 , no se ve incremento alguno de extranjeros en el comercio entre 1620 y $1640 .{ }^{43}$ Más bien parece que el auge de los extranjeros tuvo lugar entre 1580 y 1600, mientras que su presencia permaneció relativamente constante entre 1600 y $1640 .{ }^{44}$

\section{LOS CAMBIOS POR NACIONES}

¿Cómo cambió la presencia de los extranjeros de diferentes naciones durante estos años? Para este análisis se puede empezar nuevamente con las cartas de naturalización, para luego continuar con los documentos notariales. En el gráfico 4 se pueden observar las solicitudes de naturalizaciones de cuatro periodos: de 1571 a 1590 , de 1591 a 1610 , de 1611 a 1630 y de 1631 a 1650 (para compararlas con los cuatro años $1580,1600,1620$ y 1640 de los documentos notariales). ${ }^{45}$ La dominancia de los portugueses es fuerte, y sólo en el último periodo los flamencos los sobrepasan por un pequeño margen. También es notable que los italianos soliciten muchas naturalizaciones entre los años 1611 y 1630 (29), más que en todos los otros periodos juntos. No obstante, y a con-

${ }^{42}$ Fueron incluidos en el análisis sobre todo documentos que muestran la presencia extranjera. Así, partiendo del porcentaje de extranjeros en los documentos de un año, no se puede llegar a conclusiones generales respecto a la cuota españoles-extranjeros.

${ }^{43}$ Reconocemos con Díaz Blanco y Maillard Álvarez que "en los diferentes ritmos de concesiones [...] tuvo mucho más que ver la disponibilidad de la oferta por parte de la Corona que la demanda por parte de los extranjeros.” Díaz Blanco/Maillard Álvarez, “¿Una intimidad supeditada a la ley?” (nota 22), p. 9.

${ }^{44}$ El comercio general de la ciudad vivió su punto culminante alrededor de 1620: Crailsheim, Seville and the European Atlantic Trade (nota 23). No obstante, la cuota de los extranjeros en el comercio de la ciudad apenas cambió entre 1600 y 1640.

45 Basado en las fuentes citadas en nota 27. 
ciencia de la falta de solidez en el uso de las naturalizaciones como fuente para la presencia de extranjeros en Sevilla, se deberían utilizar nuevamente los documentos de las escribanías.

GRÁFICO 4: EXTRANJEROS SOLICITANDO CARTA DE NATURALEZA

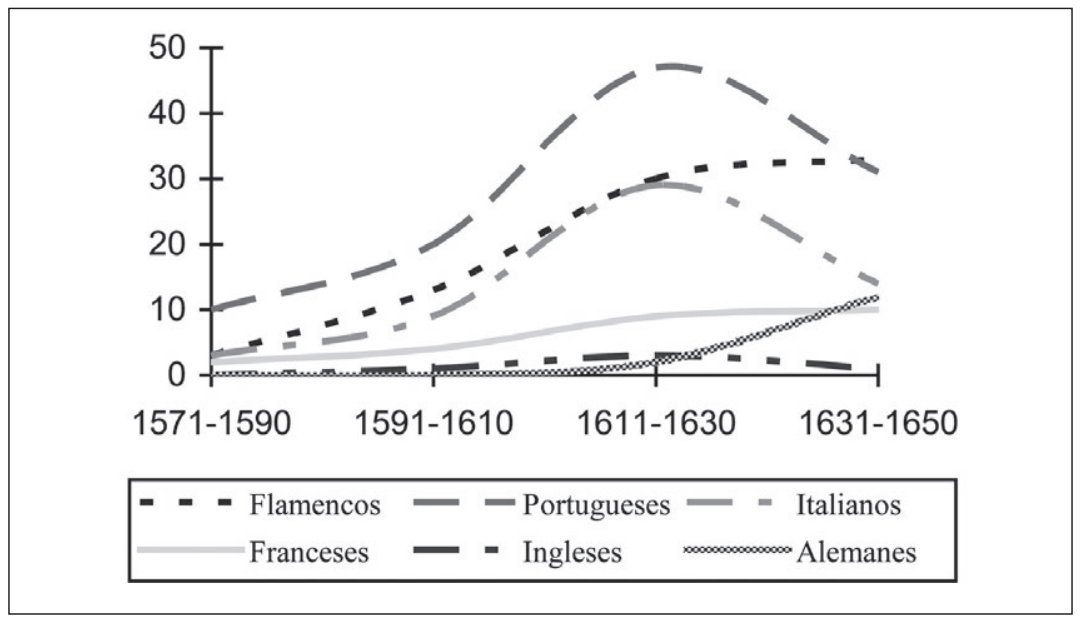

En el gráfico 5 se puede observar el desarrollo de las diferentes nacionalidades con respecto al comercio: flamencos (dentro de los cuales también se encuentran algunos holandeses), portugueses, franceses, italianos (en su mayoría genoveses), ingleses y alemanes. El gráfico muestra el porcentaje de los documentos notariales que contienen referencias a los respectivos grupos frente al total de los documentos en los diferentes años. Como hemos visto en la tabla 1, en 1580 todavía no aparecen muchos extranjeros. Es así como los ingleses, flamencos y portugueses sólo aparecen con un $7 \%$ de los documentos y los italianos no representan ni siquiera el 2,7\%. Es notable que 20 años después los italianos aparezcan en un $39 \%$ de los documentos, mientras que los portugueses sólo en un $21 \%$ y los flamencos en un $16 \%$ de los mismos. En 1620 son los flamencos los que dominan con $24 \%$, seguidos por los portugueses con $20 \%$, los italianos con $16 \%$ y los franceses con $10 \%$. En el último año, en 1640, los portugueses aparecen con la mayor frecuencia en los protocolos, pero sólo superan a los flamencos por $1 \%$. 
GrÁFICO 5: PorcentaJe DE DOCUMENTOS CON PARTICIPACIÓN EXTRANJERA

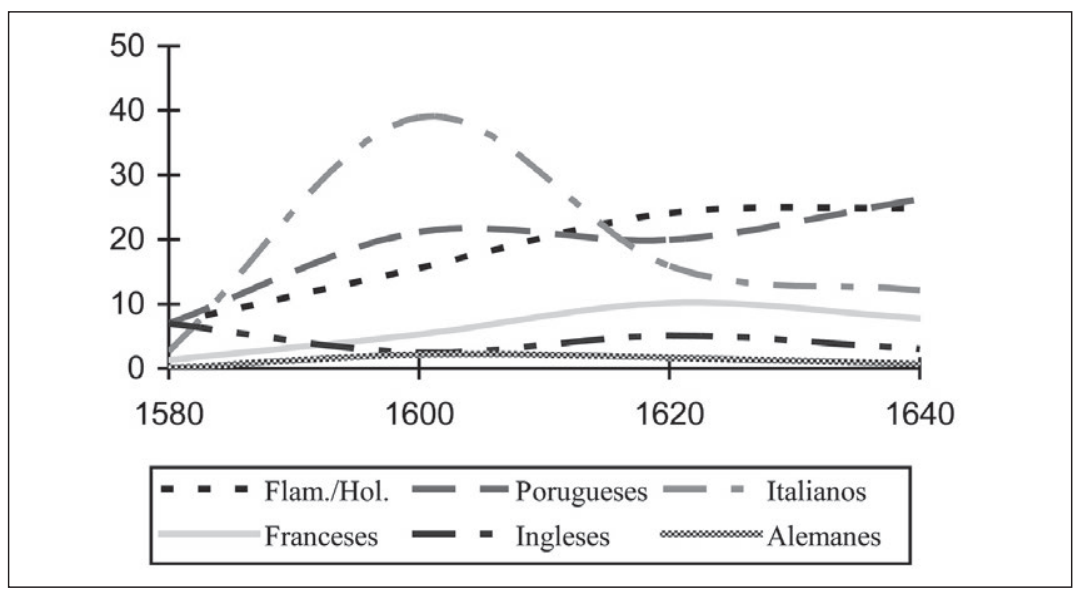

Alrededor del año 1600 se observa un pico en la cantidad de documentos con participación de italianos que puede ser explicado por la función financiera que tenían estos en Sevilla. ${ }^{46}$ Destaca el banquero genovés Jacome Mortedo, que aparece en 7,5\% de los documentos. ${ }^{47}$ Aparte de éste, había otros italianos (sobre todo otros genoveses y florentinos) que tenían sus negocios en Sevilla. ${ }^{48}$ Las demás naciones se vieron más invo-

${ }^{46}$ Francisco Núñez Roldán, "Tres familias florentinas en Sevilla: Federighi, Fantoni y Bucarelli, 1570-1625”: José Jesús Hernández Palomo (ed.), Presencia italiana en Andalucía, siglos XIV-XVII. Actas del III coloquio Hispano-Italiano (Sevilla 1989), pp. 23-49; Pedro Collado Villalta, "La nación genovesa en la Sevilla de la Carrera de Indias. Declive mercantil y pérdida de la autonomía consular": Bibiano Torres Ramírez/ José Hernández Palomo (eds.), Presencia italiana en Andalucía, siglos XIV-XVII. Actas del I coloquio Hispano-Italiano (Sevilla 1985), pp. 53-114; Pike, Enterprise and Adventure (nota 14); Manuel Herrero Sánchez, "La quiebra del sistema hispano-genovés, 1627-1700": Hispania: Revista española de historia 219, 65/1 (2005), pp. 115-151.

${ }^{47}$ Un año más tarde, Jacome Mortedo está bancarrota, dejando una deuda de 800.000 ducados. Antonio-Miguel Bernal Rodríguez/Antonio García-Baquero González, Tres siglos del comercio sevillano, 1598-1868 (Sevilla 1976), p. 174; Santiago Tinoco Rubiales, "Banca privada y poder municipal en la ciudad de Sevilla, siglo XVI": Banchi pubblici, banchi privati e monti di pietà nell'Europa preindustriale. Amministrazione, tecniche operative e ruoli economici (Genova 1991), pp. 1053-1133.

${ }^{48}$ Nombres genoveses que aparecen son por ejemplo Juan Francisco Bibiano, Geronimo Buron, Nicolao Casteleto o Lorenzo Cota. Los florentinos en los documentos eran Atanacio de Aberoni, Cesar Baroncini, Juan Felipe Bartoli, Alexandre del Nero y Luis Federigui. 
lucradas en actividades comerciales que financieras. Los ingleses aparecen sobre todo en 1580, pero van disminuyendo paulatinamente, mientras que los franceses alcanzan su máximo en 1620, apareciendo en más del $10 \%$ de los documentos. Los alemanes no parecen desempeñar un papel importante en los protocolos de Sevilla en la época investigada. ${ }^{49}$ El protagonismo tan marcado de los portugueses expuesto en los documentos de naturalización no se ve confirmado en los protocolos del comercio de Sevilla, más bien se obtiene la impresión de que estos comparten el liderazgo con los flamencos a lo largo del tiempo. Los dos grupos aparecen con un porcentaje que varía entre 15 y $26 \%$ de los documentos de entre 1600 y 1640.

Además de utilizar los documentos para analizar la participación extranjera en el comercio de Sevilla, también se pueden, mediante la aplicación de otro método, enfocar las relaciones de los comerciantes extranjeros entre ellos mismos. Para ello, se calcula la cuota de los extranjeros que aparecen por primera vez en un documento de los años investigados (gráfico 6), contando cada persona sólo una vez por año. ${ }^{50}$ De esta manera se evita que una sola persona, como por ejemplo el banquero Jacome Mortedo, influya demasiado a las estadísticas.

Gráfico 6: Presencia Proporcional de los extranjeros en el COMERCIO SEVILLANO (PORCENTAJE DEL TOTAL DE EXTRANJEROS)

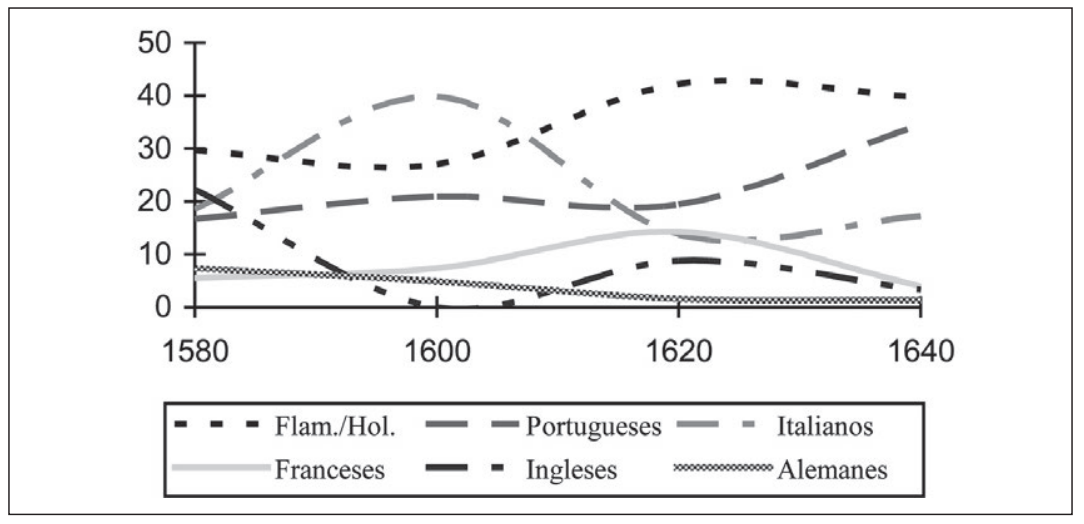

${ }^{49}$ Para los alemanes en Cádiz, presentes en épocas anteriores, véase Hermann Kellenbenz/Rolf Walter, Oberdeutsche Kaufleute in Sevilla und Cadiz, 1525-1560. Eine Edition von Notariatsakten aus den dortigen Archiven (Stuttgart 2001).

${ }^{50}$ Este método fue también utilizado para la configuración del gráfico 1. 
El resultado es parecido al anterior, pero hay varios aspectos nuevos que son de interés. Se puede ver que en 1600 los italianos siguen siendo los más dominantes, pero con un margen menor, es decir, aparecen en muchos documentos, pero los nombres se repiten. Lo mismo pasa en el caso de los portugueses, cuya participación crece entre 1580 y 1640 de $17 \%$ a $39 \%$. Proporcionalmente son menos fuertes que en el gráfico 5. Lo contrario ocurre con los flamencos que son más fuertes según este cálculo: su cuota se mantiene entre $24 \%$ y $42 \%$, siempre superior a la de los portugueses. Por lo tanto, por un lado un número menor de portugueses aparece en muchos documentos notariales. Y por el otro, había más flamencos en el comercio de Sevilla, pero aparecen en menos documentos. Esto confirma que los flamencos eran más numerosos, pero sugiere igualmente que los portugueses de Sevilla eran más activos en el comercio.

\section{LA Élite COMERCIAL DE SEVILla: EXTRANJEROS Y ESPAÑOLES}

Finalmente, se pueden utilizar otras fuentes para analizar la presencia y la importancia de los mercaderes extranjeros en Sevilla. Por causa del desequilibrio económico entre los grandes proyectos de los reyes de España y los recursos financieros del Estado, los monarcas se vieron a menudo en la necesidad de cobrar tributos extraordinarios o de confiscar dinero (por un periodo corto de tiempo). Entre los más afectados por tales impuestos o "sacas" se encontraban los ricos mercaderes de Sevilla, que contribuyeron con elevadas sumas a las arcas reales a lo largo del siglo XVII. ${ }^{51}$ Una de tales sacas tuvo lugar en 1640, cuando la penuria era tan grande que el fisco real necesitaba cuatro millones de ducados para su saneamiento. En los fondos del Archivo General de Indias se encuentra una lista de 670 mercaderes de la ciudad que tuvieron que pagar cuotas extraordinarias. ${ }^{52}$ Esta lista contiene casi la totalidad de los grandes mercaderes "del comercio universal" de aquel año, incluso los grandes Cargadores a Indias y los mercaderes extranjeros. ${ }^{53}$ Los sevillanos contribuyeron con más de la mitad de esta saca, es decir

${ }^{51}$ Enriqueta Vila Vilar, "El poder del Consulado sevillano y los hombres del comercio en el siglo XVII. Una aproximación": eadem/Allan J. Kuethe (eds.), Relaciones de poder y comercio colonial. Nuevas perspectivas (Sevilla 1999), pp. 3-34.

52 Gil-Bermejo García, "Mercaderes sevillanos" (nota 15), p. 183.

53 Juana Gil-Bermejo García, "Mercaderes sevillanos II. Una relación de 1640": Archivo Hispalense 188 (1978), pp. 25-52, aquí: p. 26. 
con 2,2 millones de ducados, lo que indica la importancia del comercio sevillano para la Corona española. La modalidad en la cual fue recaudado este tributo extraordinario para el rey consistió en un trueque de dinero en plata por cobre (vellón), es decir, en un primer paso, el rey confiscó el tributo en plata de los mercaderes para luego, después de cierto tiempo, devolverles sus remesas en dinero de cobre, que tenía un valor efectivo inferior al hecho de plata, de aproximadamente $30 \%$. Las aportaciones de los diferentes mercaderes indican su importancia en el comercio de la ciudad. ${ }^{54}$ Un grupo de 300 mercaderes se vio obligado a pagar 1.231 ducados, dando un total de 393.300 ducados. En el sector medio del comercio, 330 mercaderes contribuyeron entre 2.319 y 6.671 ducados, sumando un total de 1.131.998 ducados. Finalmente, los 41 mercaderes más ricos pagaron entre 8.847 y 17.551 ducados cada uno, totalizando casi medio millón de ducados. Es así como el $6 \%$ más rico de la ciudad tuvo que concurrir con casi $25 \%$ en el trueque de Sevilla. Esta élite comercial de la ciudad está recogida en tabla 2 con sus respectivas contribuciones en la tercera columna. ${ }^{55}$

Tabla 2: Mercaderes en Sevilla y sus contribuciones en varios IMPUESTOS, TRIBUTOS O TRUEQUES

\begin{tabular}{c|c|c|c|c|c}
\hline $\begin{array}{c}\mathbf{1 6 3 2} \\
\text { (ducados) }\end{array}$ & $\begin{array}{c}\mathbf{1 6 3 7} \\
\text { (participación) }\end{array}$ & $\begin{array}{c}\mathbf{1 6 4 0} \\
\text { (ducados) }\end{array}$ & $\begin{array}{c}\mathbf{1 6 5 1} \\
\text { (pesos) }\end{array}$ & Nombre & Origen \\
\hline 300 & 1 & 17.551 & $50 / 150$ & $\begin{array}{c}\text { Pedro Lopez } \\
\text { del Puerto y } \\
\text { Juan de Soto } \\
\text { Susana Diaz y } \\
\text { su yerno Pedro } \\
\text { de Villa } \\
\text { Vicencio } \\
\text { Miguel de } \\
\text { Neve }\end{array}$ & Flandes \\
\hline 0 & 1 & 15.375 & 0 & 0 &
\end{tabular}

54 Ibidem, pp. 25-32.

${ }^{55}$ Lista basada en datos recogidos en: Gil-Bermejo García, "Mercaderes sevillanos" (nota 15); eadem, "Mercaderes sevillanos II" (nota 53); Aguado de los Reyes, "Lisboa, Sevilla, Amberes" (nota 15); Pedro Collado Villalta, "Un repartimiento por contrabando en la Carrera de Indias en 1651. Los hombres de comercio de Sevilla": Archivo Hispalense 203 (1983), pp. 3-23; Vila Vilar, "Una amplia nómina” (nota 15). 


\begin{tabular}{|c|c|c|c|c|c|}
\hline $\begin{array}{c}1632 \\
\text { (ducados) }\end{array}$ & $\begin{array}{c}1637 \\
\text { (participación) }\end{array}$ & $\begin{array}{c}1640 \\
\text { (ducados) }\end{array}$ & $\begin{array}{c}1651 \\
(\text { pesos })\end{array}$ & Nombre & Origen \\
\hline 0 & 0 & 15.375 & 0 & $\begin{array}{l}\text { Miguel de } \\
\text { Neve con su } \\
\text { cuñado y } \\
\text { sobrinos }\end{array}$ & Flandes \\
\hline 490 & 1 & 15.375 & 200 & $\begin{array}{l}\text { Guillermo } \\
\text { Bequer }\end{array}$ & Flandes \\
\hline 0 & 0 & 15.375 & 0 & $\begin{array}{l}\text { Magdalene } \\
\text { Clut Enriquez } \\
\text { (viuda de } \\
\text { Jaques Bibien) }\end{array}$ & Flandes \\
\hline 0 & 0 & 15.375 & 0 & Ricardo Suit & Inglaterra \\
\hline 0 & 1 & 15.375 & 0 & $\begin{array}{l}\text { Thomas de } \\
\text { Mañara }\end{array}$ & Génova \\
\hline 0 & 1 & 15.375 & 200 & Juan Cervino & Génova \\
\hline 0 & 0 & 15.375 & 0 & $\begin{array}{l}\text { Gaspar de } \\
\text { Biedma }\end{array}$ & \\
\hline 0 & 0 & 13.199 & 0 & Pedro Jalon & Flandes \\
\hline 500 & 1 & 13.199 & 300 & $\begin{array}{c}\text { Simon } \\
\text { Rodriguez } \\
\text { Bueno }\end{array}$ & Portugal \\
\hline 0 & 0 & 13.199 & 25 & $\begin{array}{l}\text { Pedro de } \\
\text { Pedrosa }\end{array}$ & \\
\hline 364 & 1 & 13.199 & 0 & Lope de Ulloque & \\
\hline 0 & 1 & 11.375 & 0 & $\begin{array}{c}\text { Gaspar } \\
\text { Rodriguez } \\
\text { Pasariños }\end{array}$ & Portugal \\
\hline 0 & 1 & 11.023 & 0 & $\begin{array}{c}\text { Niculas } \\
\text { Antonio } \\
\text { (herederos) }\end{array}$ & Flandes \\
\hline 0 & 1 & 11.023 & 0 & $\begin{array}{l}\text { Francisco de } \\
\text { Conique }\end{array}$ & Flandes \\
\hline 1.120 & 1 & 11.023 & algo & $\begin{array}{l}\text { Gonzalo Nuñez } \\
\text { de Sepulveda }\end{array}$ & Portugal \\
\hline 0 & 0 & 11.023 & 0 & Ruy Diaz Angel & Portugal \\
\hline 0 & 1 & 11.023 & 0 & Diego de Payba & Portugal \\
\hline 600 & 0 & 11.023 & 0 & Nicolao de Vega & Portugal \\
\hline 0 & 1 & 11.023 & 0 & Jaques Bules & Francia \\
\hline 700 & 0 & 11.023 & 300 & $\begin{array}{c}\text { Pedro de la } \\
\text { Farxa (herederos) }\end{array}$ & Francia \\
\hline 350 & 1 & 11.023 & 0 & Pedro de Alogue & Francia \\
\hline
\end{tabular}




\begin{tabular}{|c|c|c|c|c|c|}
\hline $\begin{array}{c}1632 \\
\text { (ducados) }\end{array}$ & $\begin{array}{c}1637 \\
\text { (participación) }\end{array}$ & $\begin{array}{c}1640 \\
\text { (ducados) }\end{array}$ & $\begin{array}{c}1651 \\
\text { (pesos) }\end{array}$ & Nombre & Origen \\
\hline 350 & 1 & 11.023 & 1.500 & Lanfran David & Francia \\
\hline 0 & 0 & 11.023 & 0 & Juan de Mañara & Génova \\
\hline 0 & 1 & 11.023 & 500 & $\begin{array}{c}\text { Bernardo de } \\
\text { Valdes }\end{array}$ & \\
\hline 0 & 1 & 11.023 & 200 & Juan de Olarte & \\
\hline 0 & 1 & 11.023 & 0 & $\begin{array}{c}\text { Juan de Tapia y } \\
\text { Vargas }\end{array}$ & \\
\hline 0 & 1 & 11.023 & 0 & $\begin{array}{l}\text { Ruy Lopez de } \\
\text { Silva }\end{array}$ & \\
\hline 1.000 & 1 & 11.023 & 0 & $\begin{array}{c}\text { Francisco Lopez } \\
\text { de Talavan }\end{array}$ & \\
\hline 0 & 1 & 11.023 & 0 & $\begin{array}{l}\text { Nicolas de } \\
\text { Guadalupe }\end{array}$ & \\
\hline 0 & 1 & 11.023 & 0 & $\begin{array}{l}\text { Pedro de } \\
\text { Villa } \\
\text { Vicencio }\end{array}$ & \\
\hline 500 & 1 & 11.023 & 0 & $\begin{array}{l}\text { Francisco de } \\
\text { Ortega Saria }\end{array}$ & \\
\hline 0 & 0 & 11.023 & 0 & $\begin{array}{c}\text { Pedro Fernandez } \\
\text { de Santamaria }\end{array}$ & \\
\hline 0 & 0 & 10.558 & 0 & $\begin{array}{l}\text { Lope de la } \\
\text { Vega } \\
\text { (herederos) }\end{array}$ & \\
\hline $1.000 / 0$ & $0 / 1$ & 10.023 & 565 & $\begin{array}{l}\text { Diego Diaz y } \\
\text { su hermano } \\
\text { Francisco Baez }\end{array}$ & Portugal \\
\hline 0 & 1 & 8.847 & 0 & $\begin{array}{l}\text { Fernando de } \\
\text { Almonte }\end{array}$ & \\
\hline 0 & 0 & 8.847 & 0 & $\begin{array}{c}\text { Miguel Lopez } \\
\text { de la Barra }\end{array}$ & \\
\hline 0 & 0 & 8.847 & 0 & $\begin{array}{l}\text { Pedro de las } \\
\text { Muñecas }\end{array}$ & \\
\hline 0 & 1 & 8.847 & 0 & $\begin{array}{c}\text { Martin de } \\
\text { Sanartu }\end{array}$ & \\
\hline 7.274 & & 498.702 & 3.990 & & \\
\hline
\end{tabular}


Las columnas uno, dos y cuatro muestran la participación de los mercaderes en otras sacas de Felipe IV. Estas contribuciones tuvieron lugar en los años 1632,1637 y $1651^{56}$ y sirven para confirmar la fuerte y permanente posición de los mercaderes de 1640 en el comercio de la ciudad. La mayoría de la élite comercial participó en al menos dos de las sacas, lo que indica que permanecieron por un tiempo prolongado en la ciudad y en su comercio. Además, se pude comprobar que casi todos los mercaderes de la lista figuran entre los miembros del Consulado de Cargadores, que era la organización de los mercaderes sevillanos interesados en el comercio de Indias. ${ }^{57}$ La mayoría de ellos figuraba entre los Cargadores a Indias por muchos años.

Para hacer referencia al origen de esta élite comercial, se debe considerar la última columna, que muestra el origen de cada uno de los mercaderes, según los datos obtenidos. Con 19 nombres (sin origen indicado), los españoles son el grupo dominante, seguidos por los flamencos y los portugueses con siete nombres, cuatro franceses, tres genoveses y un inglés. Sin embargo, al comparar a los españoles con el conjunto de los extranjeros, resulta que hay 22 de los últimos frente a 19 de los primeros, lo cual señala una preponderancia de extranjeros en el gran comercio sevillano.

Los extranjeros de la élite participaron también en la mayoría de las veces en más de una saca. Además, sólo tres de los 22 mercaderes extranjeros de la élite no figuraban entre los cargadores a Indias. Estos factores indican que los grandes mercaderes extranjeros, que fueron considerados como agobio para la economía de la ciudad, residieron y

${ }^{56}$ En 1632, 72 mercaderes sevillanos contribuyeron con casi 30.000 ducados a un servicio real: Aguado de los Reyes, "Lisboa, Sevilla, Amberes" (nota 15). En 1637, 188 mercaderes de la ciudad pagaron 800.000 ducados por el derecho de la cobranza del Impuesto de los Infantes: Gil-Bermejo García, "Mercaderes sevillanos" (nota 15). Y en 1651 , alrededor de 500 comerciantes acordaron pagar 140.000 ducados por una compensación de contrabando: Collado Villalta, "Un repartimiento por contrabando en la Carrera de Indias" (nota 55). Véase también Vila Vilar, "Una amplia nómina” (nota 15).

57 Antonia Heredia Herrera, "Apuntes para la historia del Consulado de la Universidad de Cargadores a Indias. En Sevilla y Cádiz”: Anuario de estudios americanos 27 (1970), pp. 219-279; eadem, "Casa de la Contratación y Consulado de Cargadores a Indias. Afinidad y confrontación”: Antonio Acosta Rodríguez/Adolfo Luis González Rodríguez/Enriqueta Vila Vilar (eds.), La Casa de la Contratación y la navegación entre España y las Indias (Sevilla 2003), pp. 161-181. De los 41 mercaderes, sólo cinco no se encontraban en la lista de Vila Vilar, "Una amplia nómina" (nota 15), esto es Gaspar de Biedma, Ruy Díaz Ángel, Juan de Mañara, Ruy López de Silva y Magdalena Clut Enriques. Sin embargo, su participación en el comercio indiano puede ser tomado por cierto. 
comerciaron permanentemente in situ. En la mayoría se trataba de jenízaros o naturalizados que estaban plenamente enraizados en el comercio de Sevilla y no de mercaderes que vinieron a Sevilla por tratos puntuales y ganancias a corto plazo.

Gráfico 7: Composición de la élite comercial de Sevilla, BASADO EN LAS CONTRIBUCIONES AL TRUEQUE DE 1640

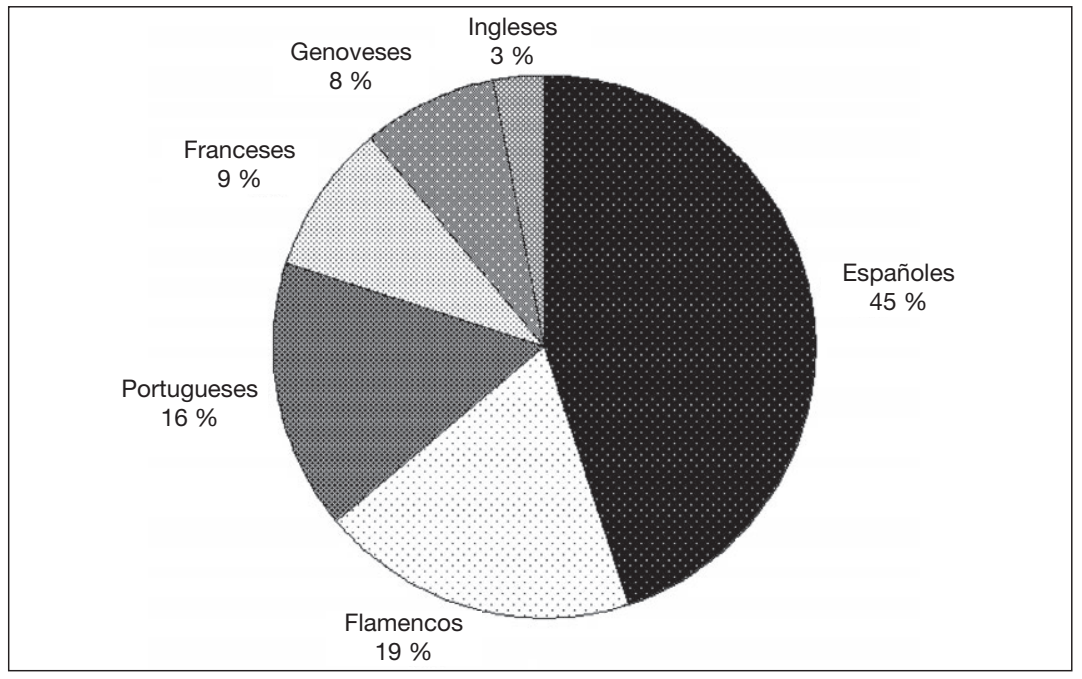

En el gráfico 7, se pueden comparar las contribuciones de los grandes mercaderes y sus naciones de origen según la lista. Es de observar que los extranjeros poseen el $55 \%$ (276.674 ducados), mientras que los españoles sólo tienen el 45 por ciento (222.028 ducados). Esto confirma que gran parte del comercio de Sevilla del año 1640 estaba en manos de extranjeros, aunque se debe decir que se trataba en su mayoría de jenízaros y extranjeros naturalizados. Entre los extranjeros de la élite, otra vez los flamencos ocupan la primera posición, adelantando a los portugueses, con $19 \%$ frente a $16 \%$, o sea 96.745 frente a 78.689 ducados contribuidos en el trueque. Después vienen los franceses (44.092 ducados), los genoveses (41.773 ducados) y en último lugar los ingleses (15.375 ducados).

Por ende, el estudio de la élite de los comerciantes de la ciudad confirma que los flamencos son los más presentes y económicamente fuertes en Sevilla, seguidos muy cerca por los portugueses. Después 
les siguen con un porcentaje similar los franceses y los genoveses, y finalmente se encuentran los ingleses (y los alemanes, mostrados en los gráficos anteriores).

\section{Conclusiones}

En el presente artículo se ha analizado la presencia y composición del conjunto de mercaderes extranjeros en Sevilla. El punto de partida fueron las acusaciones de los arbitristas a la supuesta masa de extranjeros en Sevilla que les reprochaban ser una de las causas principales de la decadencia de España. Sin ahondar en el tema de la causa de la decadencia, el artículo ha mostrado las relaciones entre los extranjeros igual que entre extranjeros y españoles durante la época del siglo de oro. A pesar de que se obtuvieron resultados ligeramente diferentes según las diversas fuentes, las conclusiones obtenidas son claras. Se puede ver que el análisis de las escribanías de Sevilla dio buenos resultados en lo referente al comercio general de la ciudad. Respecto al comercio al por mayor, las listas de los grandes mercaderes, que contribuyeron de manera significativa con impuestos extraordinarios, resultaron sumamente útiles. Por otra parte, se debe remarcar que las cartas de naturalizaciones no deben ser utilizadas como fuente única para la presencia de los extranjeros en el comercio de Sevilla, ya que el carácter especial de las naturalizaciones y la política de los soberanos españoles al respecto distorsionan demasiado dichas cifras.

En 1580 las escribanías de Sevilla no documentaron gran actividad extranjera. Ésta empezó más tarde y fue sólo a partir de 1600 que permaneció en niveles elevados por al menos 40 años. En el periodo comprendido entre los años 1570 y 1650, los flamencos representan el grupo más grande en Sevilla y fueron los más presentes en el comercio de la ciudad. En segundo lugar aparecen los portugueses, que - gracias a los grandes banqueros en la corte de Felipe IV - pudieron reforzar su posición en el tráfico indiano. No obstante, aunque a partir de 1624 los portugueses fueron ganando cierta importancia en la corte, su presencia en Sevilla no incrementó mucho entre 1600 y 1640. Durante el periodo en consideración, los flamencos seguían siendo más numerosos en el comercio de Sevilla que los portugueses. En tercera y cuarta posición entre las naciones extranjeras presentes en Sevilla figuran alternativamente los genoveses y los franceses, seguidos por los ingleses y los alemanes. 
El análisis de la élite comercial de la ciudad de Sevilla en el año 1640 evidencia varios puntos de interés. Primero, se pudieron comprobar los resultados obtenidos por los contratos notariales, mostrando la importancia de los flamencos en el comercio sevillano, seguidos por los portugueses y las demás naciones. Segundo, se ha mostrado que la élite participó reiteradamente en el comercio, lo que indica una presencia permanente de los grandes comerciantes extranjeros en la ciudad de Sevilla. Tercero, se ha hecho visible que dicha élite se dedicó mayoritariamente, y durante muchos años, al comercio de Indias. Y finalmente, se ha develado que el elemento extranjero era muy fuerte en comparación al elemento español. Entre los grandes mercaderes, los españoles representan menos de la mitad del número total y estos sólo contribuyeron con menos de la mitad del impuesto extraordinario de 1640. Esto indica que el comercio al por mayor de la ciudad y el comercio indiano estaban en su mayoría en manos de los grandes comerciantes extranjeros que estaban enraizados en la ciudad.

¿Sirven estos cálculos para aclarar las acusaciones de los arbitristas del siglo de oro español? Probablemente no, porque estos calificaron a menudo a los españoles en el comercio indiano como testaferros o meros agentes de los extranjeros y, por lo tanto, parte del problema. Sin embargo, los datos expuestos sirven para entender de qué proporciones hablaron los arbitristas en sus escrituras. Los cálculos también sirven para comprender mejor cuántos de los extranjeros participaron directamente y cuántos indirectamente en el comercio indiano, al igual que para entender mejor la estructura general del comercio sevillano con las Indias Occidentales. Por último, se puede concluir que la prohibición de extranjeros en el comercio americano tuvo muchas fallas, que se hacen evidentes sobre todo en la gran participación de flamencos, portugueses, genoveses y franceses en el comercio de Sevilla. 